\title{
Gerald Vizenor
}

Student, General College, University of Minnesota 1 and CLA - degree, 19602

Hoebel, Ad 2

Gerlach, Luther 2-3

Copeland, Edward 4

Kwiat, Joseph 4-5

Vizenor becomes journalist, Minneapolis Tribune 3

story on violence 3

African-American occupation of Morrill Hall 7-8

Native-American community, 1960s 9

American Indian Studies Department 10

Dunnigan, Tim 11

language 11

students 12

Buffalohead, Roger 13

community support in the 1960 s 14

Lukermann, Fred 15

break-up 15-16

anti-intellectualism 17-18

Beaulieu, David 21

cultural context 22

retrenchment climate 24

national problems and issues 25

Harkins, Arthur 26

other models for programs $28-30$

budget problems in Indian community $32-33$

Southwest State University - Marshall 35 


\section{Interview with Gerald Vizenor \\ Interviewed by Professor Clarke A. Chambers \\ University of Minnesota \\ Interviewed on May 28, 1996 \\ at the Home of Gerald Vizenor}

Gerald Vizenor $\quad$ - GV

Clarke A. Chambers - CAC

CAC: This is Clarke Chambers. I think this is interview \#121. I'm interviewing Gerald Vizenor in his beautiful home on Hiller Highlands in Oakland looking over the San Francisco Bay. The date is May 28, 1996.

Gerald, you come with so many experiences in your background. You are a native Minnesotan, White Earth Reservation by tribal origin, poet, scholar, teacher, newspaper reporter, social worker. Didn't you work in a prison once?

GV: I did. I worked at the state reformatory in St. Cloud. It was my first job out of college.

CAC: We can't cover all of those things. You've really have had miscellaneous career, which I think finally is a source of strength in your writing. We can't cover all of that. What we will have to focus on is the University of Minnesota. However, if you want to spend two or three minutes getting a running jump at this, that's fine. Then, you come as an undergraduate in 1956 and you're there for the four years to get your degree. You were then out of the Army; you'd had the Army experience in Japan?

GV: Yes.

CAC: Then, you come back some years later as a James J. Hill professor for a year as a special visiting dignitary. Then, you are on the faculty of American Indian Studies for six or seven years in the late 1970s and early 1980s. That's kind of the chronology. You give a running jump of what you think is relevant.

GV: I came to the University of Minnesota as a transfer student from New York University. I had gone there for one year.

Gerald Vizenor Interview 
CAC: Under the GI Bill?

GV: Yes, that's right. I came to General College for the first quarter and then moved into the Social Sciences and graduated in 1960. When I came to the faculty in American Indian Studies, I was, at the time, also teaching at Berkeley for those first three or four years during the winter quarter. So, for three or four years, I attracted enormous envy from my friends.

CAC: Yes. [laughter]

GV: I would spend a fall and spring in Minnesota and winter quarters in Berkeley. The early years at Minnesota ... American Indian Studies was politically contested at every turn.

CAC: I'm going to interrupt. Before we get into that, why don't you say something about your experience as an undergraduate student there. I know you had some really stellar experiences $\ldots$

GV: Oh, yes.

CAC: ... and I'm sure a lot that are of lower visibility.

GV: Two sides of it ... One would be where was the Native American presence at the University of Minnesota as I knew it in the late 1950s and early 1960s? It existed only in Anthropology ... some distinguished and great humanists, [Adamson] Hoebel and then some technicians who were widely recognized . . . in Archaeology for example-I can't remember his name now. I took a course from him. It was the only sort of general culture course in Native American cultures. From my perspective later; although, at the time I could not put into context my strongest criticism of such course organizations. I only knew enough to take what I could and I never really formulated, for several years, my resistance. The resistance is obvious. It's the methodology, the dominance, treating native cultures as if they are objects and also vanishing or vanished. That was pretty much the approach to natives. As I say, there were exceptions, and there are others besides Hoebel but he was a great humanist. He looked upon natives as having very active legal systems, for example . . . one of his interesting and very original research contributions. I think he may have taken up some of the influence of the structuralists that native cultures were different not lesser than western civilizations. I don't know that ...

CAC: He lived a good deal with the Cheyenne as a young graduate student and young instructor.

GV: Yes, he did. I think I only took one course about Native Americans in Anthropology and didn't find it very satisfying; but, when I was a graduate student later in the 1960s, I minored in Anthropology and took courses from Luther Gerlach who I found brilliant, complicated, a very original thinker, very ambitious theoretically and intellectually. I was stimulated by him. He had a real effect on a certain group of students and I happened to be one of them in this group who thought he was difficult but imaginative. So, it was for that reason, in part, that when I became 
a journalist and was assigned a story, following the assassination of Robert Kennedy, my first week at the [Minneapolis] Tribune as a journalist to write about why America was not-I'm emphasizing not-a violent nation.

CAC: [laughter]

GV: That was quite an assignment at the time.

CAC: Maybe that's what the city editor wanted from you.

GV: That's right. He didn't want the obvious, the popular cultural notion. He wanted me to argue why it was not, which means Frank Premack, the editor then, believed that, in fact, it was not, relative to other nations, etcetera. I called Luther Gerlach and did an extensive interview, which became the basis of the story. He argued just that, that these horrible instances of violence and assassination do not make us a violent nation. They, in fact, tell us something else about power, about accessibility. It was a very, very good foundation for this essay I had to write, a feature story.

CAC: But, your heart was not in it?

GV: Oh, no, it was, very much; although, it was difficult for me to approach it this way at first. It was quite a challenge for me because I was convinced that . . . How long had I been alive then? Thirty years or so. This was, from my experience, a very violent time and a violent nation; but, relative to American history, it was not. My father was murdered at a time in Minneapolis when it was a very violent America and violent city ... I think thirty some unsolved homicides in that year alone.

CAC: I'm going to interrupt. This can become a conversation. I'm not going to say much about myself; but, last fall, I had a call from a reporter in Washington, D.C. saying that she had remembered a special lecture I had given on America as a violent nation. She said, "It was in November of 1963, and you threw your notes aside, and you talked not of the assassination of JFK [John F. Kennedy] as an aberration but as ... that we'd always thought of ourselves as a peace-loving people. What do you think now?"

GV: Ah! [laughter]

CAC: I had no memory of doing this at all. I think her memory was probably an accurate one. Quite often I would take off from some current ... I was on the other side-still am.

GV: I wrote this story in 1968. Gerlach's point was structural relationships, power, poverty, and accessibility, of course, and while the means of violence are probably more available to Americans, firearms, than in other nations ... In any case, it was quite a challenge and I 
thought at the time, a very good story, and a solid argument, and a good consideration at the time.

CAC: As an undergraduate you'd had some master teachers who really touched you?

GV: I did, indeed. I think I'm lucky in that way. I think anyone coming through institutions ... so much of our contact is chance, coming to the attention of someone, finding someone who is an inspiration. We're not all at our best everyday; so, if someone hits you on a bad day, they think you're worthless. I suppose the most inspiring for me was Edward Copeland who taught in East Asian Languages. He was a scholar in Japanese language, and literature, and art. I came to his course, in the summer, on Japanese Literature in Translation, a subject that drew my attention romantically and historically when I was in the military in Japan. Copeland had such an influence on me and inspired me in both literary imagination and also scholarship that I took everything he offered.

CAC: They were tiny classes.

GV: Yes, they were seminars and that was a blessing, too . . except the art class was quite large. I say, large; it was maybe forty or fifty people. I completed a minor as an undergraduate and pursued graduate study in the East Asian Area Studies; but, by that time, I had become so active politically and institutionally active in native movements that I just couldn't hang onto the aesthetic pleasures of literature. I was running so fast, I could hardly ...

CAC: [unclear] before this, or during this, or after?

GV: Some during but mostly before.

CAC: You had a running jump at it.

GV: Yes. [laughter] There were other people who moved me; but, Copeland was the most inspiring and also a lifelong friend.

CAC: He died recently?

GV: Yes, he did.

CAC: You're mentioned also in our conversations around and about, Mr. [Joseph] Kwiat in American Studies is someone who...

GV: Yes. I love telling a particular story about him. I think as a sophomore I took a course in American Literature, one of the beginning courses. He must have just been starting out as a teacher himself. He was very dynamic, very [unclear], and like to prop his one foot up on a desk. He paraded around a lot. He was very friendly and warm. He almost filled the room. 
I see him now as much bigger, I'm sure, than he was physically, as I remember him. I was very critical of a lot of theoretical interpretations, at the time, about literature. Some of my readers today would find that quite amusing I'm sure. [laughter]

CAC: [laughter] Different theories.

GV: At the time, of course, I would have been critical of the modernists and also of new criticism where there was such an indulgence in discovering the text only on the page. I would have been arguing, I'm sure, for the presence of the author, the intention-that terrible word in literature - of the author.

CAC: Try it in History.

GV: Yes. He tolerated this and I'm just guessing now that the reason he did was he liked the stimulation of a little bit of disagreement. I wasn't nasty, of course, or he probably would have thrown me out. I just raised these questions and he rather liked that kind of discourse; but, I must have gotten peevish because I kept doing this. Finally, he just stopped me and delivered a lecture directly at me for the whole class. It went something like this: Vizenor, before you can be an anti-intellectual, you must first be an intellectual. [laughter]

CAC: [laughter]

GV: That was a vital lesson.

CAC: It's the kind of teaching that many of us did not engage in, that is, really polemical, and singling out, and not belittling you but criticizing you.

GV: Yes.

CAC: No one has commented about Mr. Kwiat very much because he was not a publishing scholar. When people talk about American Studies and he kind of falls off the map. But, he was a very fine violinist and played in a quartet.

GV: Is that right? I didn't even know that.

CAC: I think that that kind of cooperative energy that's required in a string quartet played out in the way he handled the classroom. That's speculation. It's a little known fact; so, I throw it in for posterity.

GV: Probably one of the most despicable teachers I ever had at the University of Minnesota was ... These are just the extremes now. Copeland and Kwiat would be my best memories of intellectual development and inspiration. The killers... those killers of the dream of imagination are also there. Most of them, I would drop. I'd find this out in a week or two and 
drop them and move quickly to another course; but, I got stuck in a course taught by Franz Montgomery.

CAC: He shows up in one of your stories as Monty Franzgomery or something.

GV: Yes, right. He was just a dreadful teacher. I'm sure there are people who found him inspiring; but, for me he was dreadful. He was hostile. He was elitist. He was uncompromising. He was very militaristic about literature. I just have the most dreadful thoughts about him. There were many other teachers, too, that were very good in the classroom and had a very positive effect on my kind of thinking. I was very eclectic and complicated, to say the least.

CAC: How did you make your way for four years, you and the GI but that didn't fill all your needs. Were you working?

GV: I always had part-time jobs. In the summer, I worked as a house painter. That was my father's and my uncle's occupation. The name was good. Vizenor was a good name in house painting; so, I never had any problem finding jobs. I did my own contracting. During the school year, I worked in the library for a couple of years. I was a page down in the stacks. I loved that ... the old library. The new library, I don't think I'd like as much. I liked the dumbwaiter, and call slips, and pneumatic tubes ... that's a great nostalgia. I worked as a librarian in Anthropology. I think I was the first person to establish that. I also worked in an animal laboratory ... university jobs of different kinds over the four years.

CAC: Did you work with Eldon Johnson at all in Archaeology?

GV: I wouldn't work in Archaeology. He taught the cultures class. Later, when I was a journalist, I wrote a story about his work in northern Minnesota and I was quite critical of the way human remains were being treated; so, we didn't have much to say after that.

CAC: I know him in his later career and I think he took it to heart. He may not have said that to you; but, I think that he came to be quite sensitive to that issue.

GV: That's very good.

CAC: When one thinks about the history of the University of Minnesota or of higher education generally, the late 1950s are thought of as sort of [unclear]; and it's only in 1958, 1960, 1962, 1964 that things begin to happen, in part because money begins to come into the system. This is a number of plateau years . . . there wasn't much excitement on campus, I'm suggesting.

GV: Quite true, yes. The construction was just beginning in the late 1950s, which is still going on.

CAC: Then, you did graduate work also part-time when you were doing these other jobs? 
GV: When I graduated in 1960, my first job was at the state reformatory as a social worker, or what they called a corrections agent, doing social work inside the prison. A year later, I entered graduate school?

CAC: Part-time?

GV: No, I was full-time at first and then continued part-time ... I think all together maybe three years full-time in graduate school. Then, as I said, I was so active in things that I . . .

CAC: This would be active off campus because ...

GV: Yes, yes. No, not on campus. At the time-this would have been early $1960 \mathrm{~s}-$ there was not much going on on campus. It wasn't until the late $1960 \mathrm{~s}$ and then I was a journalist. In 1968, I became a journalist for the Minneapolis Tribune. I wrote about issues on campus quite often, including the occupation of the president's office.

CAC: Which one? The African-American?

GV: Yes, African-American.

CAC: Do you have memories of that that you would like to share?

GV: Yes. There was a big meeting. I don't think I'1l use the name of the student. You'll understand when I tell the story. One of the leaders, there were several, but one of the very powerful and articulate leaders had been at the state reformatory when I was there and he was one of my cases; so, here I am inspired by his leadership and then trying to pose the obvious objectivity of journalism when every story is always more complex than just dropping in as some pure objectivism. I was completely humiliated by the best of intentions as a journalist. There were a lot of journalists there. I think this big meeting took place in the Coffman Union. They were meeting in private and then came out to have a little chat with journalists and decided, in fact, that they weren't going to talk because the journalists had not treated them fairly . . . "except for one person." There must have been fifteen to twenty journalists there of different kinds, radio, television, and print. Of course, people were kind of looking around wondering who that sellout is. Then, my ... names me . . . [laughter]

CAC: [laughter]

GV: . . . as the only journalist they would trust and summons me to the inner chamber. I say, "I can't do that." He said, "No, you have to." I go in there to tell them that I can't do this, and why, and that I've already been discredited by your favor.

CAC: Discredited with your fellow correspondents? 
GV: Right, of course. I walked back out immediately but it still had it's effect. Everybody thought I had some inside connection. The consequence of this is that the Tribune sent over another reporter, which made very good sense; so, we jointly reported it. So, it wasn't a set up.

CAC: So, there's no inside story. Too bad.

GV: No, no.

CAC: This was really the first student movement-it was largely a student movement-urging the creation of a studies department, in this case, for blacks or as it came to be Afro-American Studies. Then, others came after: Chicano, American Indian, Women. Did you cover those, too?

GV: Yes ... I don't recall doing any work in the feminist movements or Women's Studies except insofar as they were active in other movements: the peace movement, environmental, and anti-Vietnam war. I just thought about another case at the reformatory, a case I thought had been a real injustice. Again, I won't use the name. I took this case up because no one else would talk to this inmate. He committed, personally, no violent crime; but, he was present in a car when one was committed and that's as much of the guilt. For purposes of understanding these issues, he was not a violent person in those terms. He just had terrible luck. Nobody would talk to him and he was passed over several times for parole. I took up his case. I was successful; although, it was very, very difficult. I don't want to go into that part of it except to say I found him very bright, very effective, a complicated and a difficult person but a solid strong imagination. I led the way for him to get into the University of Minnesota right out of ... In fact, that's how I arranged it. He was a student there when I returned as a journalist. He was very active politically not only at the university but in the community and then also in Mississippi during voter registration. The sad thing was that it was his leadership in the Mississippi voter registration that led to his violation of parole and return to prison. He had left the state without permission ... terrible. That so embittered him. Of course, it would. Doing good things and having a narrow minded bureaucracy that could not see the honor of this ... just on a technicality, throw him back in prison? Great service, great service in protecting the community? It embittered me, too; but, it particularly embittered him and he never recovered from that. I don't mean he turned to crime.

CAC: He never came back as ...

GV: He never came back.

CAC: You were a reporter-I'm guessing ... I don't know whether it's the case-when the American Indian Studies program was established?

GV: Yes.

CAC: You followed that from the outside then? 
GV: Yes.

CAC: You were through with your graduate ...?

GV: I'd been very active in native community work-Franklin Avenue started a service center-and then also on reservations, in various ways and various kinds of issues. That was the beginning of a lot of urban movements around the country. I have to say-it's self serving-that Minneapolis, partly under my leadership and even before AIM, the American Indian Movement, was the most active in urban areas. We organized a protest against the Bureau of Indian Affairs and effectively brought the Bureau of Indian Affairs to admit that the so-called law they had been standing behind did not exist, that law being, we only serve Indians on or near reservations. That was not the Congressional intent and was not part of the law. Then, Congressman [Donald] Fraser took up our issue, and did congressional research, and discovered, in fact, that this was not. So, our protest changed this bureau practice so they then had to support urban programs where natives . .

CAC: Was this in the late 1960 s?

GV: This was 1965 and 1966.

CAC: What would have been the urban population of Native Americans in Minneapolis, most of them clustered in the Franklin Avenue area, at that time?

GV: Estimates ranged from 5,000 to 15,000 .

CAC: A lot of these were drifting back and forth to different reservations? [unclear] Ojibwe and Dakota?

GV: Mostly Ojibwe or Chippewa, probably 90 percent and mostly living in the Franklin Avenue area; and that's where I opened that store front, that service center.

CAC: What role did the American Indian community play in Minneapolis in the establishment of an American Indian Studies program? What were the initiatives? Where did they come from and how do they mesh? Who were the chief characters here?

RV: Roger Buffalohead was the first chair.

CAC: He had to be appointed by somebody. Who were the point persons in the university for the creation of this [unclear]?

GV: I don't know that. That's interesting. I can say that the unusual part of that creation was that it was within a division, Social Sciences; so, it had divisional support initially. 
CAC: In the Arts College?

GV: Yes. That's unusual because these programs were hardly ever created as whole departments right off. At Berkeley, for instance, ethnic studies brought together the four sort of food groups ...

CAC: [laughter]

GV: ... the radical minority food groups, African, Asian, Chicano, and Indian. Of course, no division would take this on; so, the department, for twenty some years, floated out of the chancellor's office as an additional kind of department.

CAC: At Minnesota, it would be strange to have it in the Social Sciences because one of the first additions were people who would teach basic language?

GV: That's right.

CAC: And also History, which is kind of a humanistic discipline?

GV: Yes. It was mostly social science and historical at the time. Language came later.

CAC: Language is not part of . . these older women who were native speakers?

GV: They came later. The idea of teaching language was part of the formation; but, no one had such experience and there were no lesson plans, there were no lexicons. The only lexicon that existed was dated in 1858 . While this was an ambition ... then in fact, there were many native speakers of Anishinabe. It still was an language that was not active. It was an oral language for the most part and it was also clearly identified as an important aspect of identity and cultural distinction.

CAC: Accurately so.

GV: Yes. For all those reasons, it was part of the original idea of almost all native studies programs in the country; but, few of them have actually carried it out with such distinction and credit as did the University of Minnesota in American Indian Studies.

CAC: How does that come about? Why is Minnesota able to do that, lacking models elsewhere really that are applicable?

GV: I can't be definitive. I can only apply my general knowledge here; that is, I can't cite someone's decision. Minnesota was unique in that it had primarily one language group, Anishinabe and then ... 
[End of Tape 2, Side 1]

[Tape 1, Side 2]

GV: So, it was easy to identify the significant primary languages of the state. Whereas, say, in California, we have hundreds of languages; so, it would be difficult identifying which language. You're in a lot of political trouble without that-in fact, that has been the case here at California. I think at Minnesota there also had been a number of very active people. Tim Dunnigan, for instance, was a very active anthropological linguist. Several things had to be developed: orthography, an orthographic system for writing it, and a method to teach it. Just being a speaker of it is not being a teacher of it. It had to become a written language so that it could be taught as a language in an academic situation.

CAC: These recordings done back in the 1920 s and 1930 s . . I'm trying to remember the name of the woman who did those.

\section{GV: Frances Densmore.}

CAC: Yes ... did that have a bearing on this at all?

GV: I don't think so. Those recordings, [unclear], were not of high quality and, furthermore, many of the words that the singers were singing were in song and were archaic even to the singers, which is true of much song. You can't really break out the linguistic meaning of the word in a song. There were many speakers around; that was not the difficulty. It was finding people who could be trained to teach and that's what Tim Dunnigan did with a ...

CAC: He taught these older women?

GV: He taught the teachers how to teach. They were native speakers and he worked with them to develop all of these materials. It is one of the most significant native language projects in the country. Tim Dunnigan, who never sought much public recognition for this ...

CAC: He was very modest.

GV: . . . is very modest. He did very serious work among the Hmong in Southeast Asian languages.

CAC: Did you become a speaker himself?

GV: Oh, yes.

CAC: I was going to add that because after you left, his work with the Hmong was really spectacular. 
GV: Yes, I know.

CAC: They had no written language at all.

GV: No. He's an extraordinary and dedicated person and largely uncelebrated for this great work.

CAC: He had to be set free by the college to do this.

GV: He was. He was hired in American Indian Studies to do this work. He had a full-time appointment just doing this. That was very unusual. Again, it was possible because the political difficulties in selecting which native language to teach was largely eliminated by the fact that the primary speakers were Anishinabe or Chippewa and Lakota or Dakota.

CAC: They did start with both the Dakota and Anishinabe, as I recall.

GV: Yes, they did. The other side of this is, how about the constituents? How about the students? The enrollments were very small, of course. They grew smaller by the week through the term. No one can adequately explain that. It certainly isn't popularity because everyone would say, "This is critical, and important, and a necessary part of identity, and important to the nation's history, and the state's sense of things. The university should do this, of course." I don't think anyone ever argued against any of those ideals; but, the constituency didn't carry out those ideals in a way that would serve this ambition. You had to raise questions at the end about whether this was really worth it as an investment.

CAC: So, there was not quickly a significant mass of students prepared to . . . ?

GV: No. Serious students, in small numbers mostly ...

CAC: How many non-Indian students came in?

GV: .. . not at first, but shortly thereafter mostly. I think probably what might have happened is that native students come to a language. It's their language. They know some of the words. They learn some of the structure, and then feel comfortable with it, and then realize after one quarter, that the study of any language is very difficult and time consuming. It takes great dedication. Putting that in the context that attendance and completion of courses by native students in the department was very low ... In fact, Dave Beaulieu reported near the last days of the department that a study of courses completed by Native Americans in the department showed the majority of all those credits were taken as incomplete. At the time, it would have been a terribly embarrassing bit of public information that a very high percentage was incomplete. 
CAC: I'm sure that efforts were made to create a home there on campus for Native American students?

GV: Yes.

CAC: You had a rotating series of directors or chairs, whatever they were called.

GV: They were chairs.

CAC: Was the first one Buffalohead?

GV: The first was Buffalohead.

CAC: He's a Ponca?

GV: Yes. He fulfilled, as did the next couple of chairs, the popular saying that Chippewas are only governable by somebody from the outside. That a Ponca would be admired in this situation fulfilled that generalization about Chippewa leadership. [laughter] He was very good. I found him personally moody, detracting, sometimes duplicitous, and bitter about much of the experience-rightly so-at the university. I must also add that I wasn't his student. Students raved about him. They loved him. He was generous, very supportive, gave much attention, was always available, and was very active in the community. I don't mean he was a protestor or a sign carrier. He was present. He would show himself and be present in many community events.

CAC: Was there a community component of the governance or was there an advisory group from the community to assist this program? The Afro-American Studies had a lot of black leaders who had access to Morrill Hall and they were over when things weren't going right. They'd go to the president. They knew enough not to stop off at a lower point. What would be the case with the American Indian?

GV: There were two sources of leadership here. One is the state itself, the native reservation governments and organizations that, of course, were part of this from the beginning . . long . . . way back in the 1950 s were very active.

CAC: Such as?

GV: The Nolte Center [for Continuing Education] held a conference in the 1950 s on the issue of reservation governance and something equivalent to sovereignty. This was a major conference. I must say I came across it by chance. When I was working in the library, I found mimeographed-they were mimeographed in those days-copies of reports, minutes, testimony, and transcripts from those meetings. They were 1953 and they largely focused on the issue of Public Law 280, which was legislation granting the state government certain legal rights on 
federal trust land. There were arguments for and against this. Largely, the issues focused on the sense of sovereignty or independence and what this meant, and states rights and sovereignty, and native trust land sovereignty.

CAC: Did the state historical society have any connection to these conferences?

GV: No, the governor's office did. They had an appointment of some director of state Indian-I don't know what the title was at the time-Affairs. Again, the state was active, has been active for a long time and so have tribal leaders.

CAC: When they came on campus, did they confer with deans and vice-presidents?

GV: Probably not in that case. Another very active group would have been the very few native graduates from universities and colleges in the state. At the time I graduated there in 1960, there were, I think, if I remember accurately, about thirty-five of us who had graduated from a college or university. But, by the mid 1960s, many natives were in the beginning of Indian organizations. That would have been the Civil Rights Act, the Johnson Administration, and the formation of these community action programs. These were-I don't want to say revolutionary-very inspiring and stimulating because the federal government, in fact, was ready to hand out money to do things ...

CAC: Ready and did.

GV: Yes . . that were not bureaucratic, that were not going through existing federal or state agencies; so, I was active in that, of course, and so was everybody I knew. That had a real impact on all of this. To say that there would have been three or four people . . there were so many people part of this; but, also, there was a national movement to create these studies programs.

CAC: How many were there across the whole country finally?

GV: Say, by 1970 , there might have been maybe a dozen; but, they wouldn't have been full departments.

CAC: How many of them survive?

GV: Very few now.

CAC: Arizona ...

GV: California . . California is on its last legs here. There are many programs. I'm referring to full departments that have departmental status. Programs . . . a larger number . . . in fact, they have grown and they would be of different kinds. They would be people who have appointments 
in other places who come together in a program which doesn't hold tenure or, in fact, a tenure holding program ... a lot of different kinds of structures and configurations of how native studies is focused on in universities or colleges.

CAC: I'm speculating-I may be off base but I'll try it on you-that from within the university, Fred Lukermann, who was assistant vice-president for Academic Affairs with Gerry Shepherd, may have been the outreach person in the American Indian Studies.

GV: He was from the beginning.

CAC: Can you say something about ... my speculation is accurate then.

GV: He was a very strong supporter of Native American programs in particular but also minority programs in general. I've always known him as articulate and strongly supportive from beginning to end of the American Indian Studies Department at Minnesota and I'd say responsible to the end. In 1982, when American Indian Studies went through yet another chairperson and was clearly ungovernable, Lukermann sent us each a memo and said, "You have one academic year to put together governance, get your house in order, and govern yourselves or you're finished." I don't know if he used that word. Of course, nobody thought about it. The year went by, and now we're in spring, and nobody is thinking about it. Lukermann reminds people that if they can't put together the governance of the department, they probably should look around for another academic home.

CAC: Because some were tenured?

GV: Yes, most of us were. I saw that nothing was about to happen here. In fact, it was even worse than it had been. It was destined for total dissolution. Tim Dunnigan went to Anthropology. Russell Thornton had already gone to Sociology. Buffalohead had left the university earlier. I went to American Studies. Dave Beaulieu took early retirement, etcetera, etcetera.

CAC: How about those older women teaching the languages? What happened to them?

GV: They cut down some of the language teachers; but, they carried the languages into ... I think the kind of floated for awhile in Humanities. I'm not sure. They didn't eliminate it. Lukermann carried them into ... and Dunnigan continued a relationship with them.

CAC: All of those you mentioned have American Indian background?

GV: Yes, yes.

CAC: Including Dunnigan? 
GV: No, he's non-Indian.

CAC: He would really be unique. He was learning these languages on his own?

GV: Yes. He was the expert in linguistics that could put together the programs.

CAC: I'm going to back up three minutes . . . really the programs become ungovernable. African-American Studies went through not quite the crisis but they had a larger body of persons to work with. Women's Studies went sailing along just fine. Can you describe the difficulties within American Indian Studies? All of you who were tenured scholars and men of real note in your own right; but, it didn't work?

GV: There wouldn't be an easy generalization to either explain or even suggest why it didn't work. A lot of bits and pieces and for different individuals, these different bits and pieces and political parts had more impact than on others. For instance, Roger Buffalohead took the greatest beating by racists in the early formation of American Indian Studies. It was new. It was insignificant to a lot of people-still is to a lot of people. He was the front line there and he took the beating. He was very popular in the native community and nationally among natives as a leader, an academic leader. This was new and he was a spokesperson, very articulate . . . for me kind of moody and sometimes desperate but very articulate, and very effective, very smart. He didn't write very much. He was not appreciated by other academics in the university. In fact, I'm going to guess that they were probably very suspicious of him. They had no way to know him.

CAC: Clearly, with Buffalohead in History that was the case and he was appropriately suspicious of us.

GV: Yes. The university would have little way to know him except, say, by committee or by publications, and he didn't have much publication, and I gather he did less and less committee work because it was not pleasant. While he was very popular with the community, he had less and less credibility in the university. They decided to change this around and bring in a chair who was a strong academic, a native person, who would have the respect of his colleagues at the university and who was not necessarily strong in the community, meaning radical movements, things like that. That was Russell Thornton. That didn't work either. While he did have stature among university colleagues, he didn't have much stature in the community and he was an outsider, too.

CAC: He had made his mark even when he was at Minnesota in demography and in the decline of Indian population, right?

GV: Yes.

CAC: I gather that holds up still very well? 
GV: Oh, very well. Again, politics have changed. At the time, identity politics was very powerful. It still is but in a different way now.

CAC: What was Thornton's tribal background?

GV: Cherokee. Nobody really knew much about him. The urban community was also strongly influenced by the American Indian Movement by this time. Their effect upon the department and the university, in my view, has been nothing but negative, detracting, destructive, and, in the end, probably destroyed the whole damned thing. They would come to campus and bad mouth every teacher and every student for being untraditional and ... a waste of time. You should be working for your people ... that sort of thing.

CAC: I see.

GV: They bred enormous guilt, and hatred, and suspicion.

CAC: At that time, Russell Means?

GV: Not so much Russell . . . Clyde Bellecourt, Dennis Banks.

CAC: You say not Russell Means?

GV: Russell was more active at that time in Ohio and what South Dakota. It's a little later that Russell is . . Russell was not the primary player in Minnesota. He was part of the national AIM.

CAC: These two fellows coming on campus would certainly have an impact on Native American students, I should think and it would be hard to resist that.

GV: Many students, of course, identified with this kind of movement, wanted these radical leaders to come on campus and say a few good critical words about the faculty and that sort of thing. It was, for the most part, an anti-intellectual department. Intellectual interests were suspect as being anti-traditional. It was a very difficult struggle.

CAC: There was no other ethnic or minority group that has to face that as severely as the Native American, right?

GV: Quite true. Politics were just as severe.

CAC: After all, you have W.E.B. Du Bois to appeal to ... a long tradition of black scholarship.

GV: We were all seeing anybody who wrote or had any intellectual interests-God forbid you should speak comparatively or theoretically. You were judged to be non-Indian. That's not 
Indian. That kind of thinking is against tradition. You should serve your people. In other words, you should be a foundationalist, a fundamentalist, an essentialist. This was very destructive, very, very destructive. It made teaching in these programs-and it does today-very difficult. In fact, my guess is that in the next generation when somebody, if they do, looks back at this trying to understand it ... Why did it not work? Why have so many native scholars gone into traditional disciplines rather than ethnic or native studies? Probably a good strong argument to explain this will be, that it's essentialist, and that these kinds of forces are antiintellectual, and you just can't developed intellectual . . .

CAC: When you use the word essentialist, what are you bringing to that?

GV: That just being Indian is the essential and only meaning that gives meaning to this. That's how you explain everything ... as the essential sort of traditional value.

CAC: It's in essence.

GV: Yes, rather than questioning things or discovering things by discussion. My argument about this is taken much better now than it ever was then, of course-I don't even think I had an audience then-and that is, what's traditional about native consciousness is discourse engagement.

CAC: Ah!

GV: That's what's traditional. But, what these guys were peddling was lower case fascism, dominance, authority. They were fundamentalists in every sense of the word, and they derived their power from these very simplistic fundamentalist ideas, and they called that tradition. What do they know about tradition?

CAC: Some of them, at least, were able to make a good show with the non-native elites by playing Indian.

GV: That's right, who supported this. Many liberals supported this.

CAC: Oh, yes.

GV: They thought this was a knowable tradition. They thought this was a knowable and fundamental tradition because the view was that Indians were long gone; so, what we have is this kind of objective legacy. For generations, Americans, through popular culture and the institution, have been taught to look upon Indians, methodologically speaking, as objects.

CAC: Right.

GV: So, now we have a liberal sentiment and consciousness with just a little bit of romance that the Indian is coming back with his traditions. It also supports this kind of objective sense of 
tradition, that you can know it. It's an object that you can know. When, in fact, consciousness arises from immediate experience, some historical memory, and you have to hash it out to give it some meaning in the moment. We were being delivered these essential fundamentalist . . . something equivalent to Christian fundamentalism, disguised as Indian values.

CAC: In the early 1970s and mid 1970s, I did a certain number of workshops as an historian of welfare with social workers around the country ... four or five of them. There was one in Portland, for example, and the social workers, oh, boy! they were far advanced liberals. Right? They would strive to find a local Indian speaker to come in and open with an Indian prayer.

GV: That's right, yes, and these are secular people.

CAC: Then they'd go away. I remember they'd come in . . . we were sitting there . . .

GV: Deeply touched.

CAC: Yes. [laughter]

GV: The earth messengers, right.

CAC: And nothing happened. Some ritual of satisfaction that makes some of these liberals feel pretty good.

GV: Yes. It always amazed me ...

CAC: Of course, they came with feathers and beads ... you know that better than I.

GV: Essential stuff. As if somehow that had some meaning in the context of a liberal, secular institution. They would never invite a Nazarene fundamentalist preacher to come in do the . .

CAC: [laughter] We had him on our faculty.

GV: Oh, you did? [laughter] Tim Smith.

CAC: Tim Smith was a Nazarene minister on our faculty.

GV: Is that right?

CAC: During the later 1970s when Lukermann was dean and out of the vice-president's office in Morrill Hall, he tried to attract your novelist friend from New Mexico to come and be a distinguished member of our American Indian Studies. 
GV: Momaday.

CAC: N. [Natachee] Scott Momaday. Were you aware of that?

GV: There was a move very early to bring Momaday in as not only administrator but a senior faculty member in American Indian Studies and English. Yes, we knew about that. Momaday, at the time, of course, had so many offers.

CAC: Oh, he must have.

GV: He was at Stanford on the faculty; but, then he took an offer at Arizona where he still is.

CAC: Probably around the country, Arizona has the most stable and the most respected program?

GV: It is a strong growing program now; but, it went through some difficult times in the past decade.

CAC: If Momaday has been there for ...

GV: He was the first person there. They didn't have a program when they brought him.

CAC: I didn't know that.

GV: He came in the English Department. So, the department followed him. They also hired Vine Deloria. They were going for the most significant scholars and writers at the time.

CAC: I'm thinking that this was not a search by the American Indian Studies program but by Lukermann ... really going out by himself trying to attract these people to Minnesota.

GV: The native community strongly supported such an approach. I don't know how many offers Momaday must have at the time but surely half a dozen or more institutions tried to attract him because he was the premier Pulitzer Prize winning native property.

CAC: He was very impressive and lovely.

GV: A fine speaker and good teacher.

CAC: Lukermann had Florence [Mrs. Clarke Chambers] and I to dinner at the Blue Horse with Momaday to persuade him ... to show him that we had good food [unclear] congenial ...

GV: Yes, yes. [laughter] 
CAC: It didn't work.

GV: What was the date of that?

CAC: I'm guessing it was 1977 or $1978 \ldots$. . I don't know.

[break in the interview]

CAC: The American Indian Studies Department had really floating leadership. It was in and out. No one stayed longer than one or two years because they were discouraged with the burden that they had to pick up. Could you say something about some of them. You have spoken about Buffalohead and a bit about Thornton. Do you want to say a bit more about the others?

GV: I think just as sort of brief generalizations characterizing their leadership and their support and their constituency or strongest constituency ... Buffalohead was very popular in the native community and not so popular among university scholars.

CAC: His role in History was so quiet. I was chair when he was chair. I'm sure I didn't do it well but I tried to encourage him; but, he just could not-maybe wisely-or wouldn't make that commitment.

GV: Russell Thornton was a strong scholar, very tenuous, maybe weak in connections in the community. In fact, he didn't earn very high community support. The view among many people was that he failed because he just didn't have community support. I want to come back to this community problem in a minute.

CAC: Okay.

GV: Then, they brought in Dave Beaulieu who was a university Ph.D. in Education and also very active in the community and had worked in other native...

CAC: What was his tribal background?

GV: Chippewa. He was very active and also popular in a sense. He'd been so active for so long, he was well-known in the community. He was not, probably, the most effective administrator at the time...

[End of Tape 1, Side 2]

[Tape 2, Side 1]

CAC: You were talking about Mr. Beaulieu in the last months and year of the program. 
GV: There were different kinds of leadership that responded to different critical demands within the university, that is, the way the university faculty interpreted what would be the most effective leadership to serve the department but also the community demands. These never really came together in any convincing or supportive way, partly because of the American Indian Movement influence. That was powerfully fundamentalistic and anti-intellectual. But, the community was changing at the same time that the university was, and it seemed to me that always the idea of who would be the most effective leadership here was a defensive one, and there was always some kind of outside influence in delivery because the department just didn't function well. This was new. There had never been anything like it. The University of Minnesota Department of American Indian Studies, as is true of almost every other native studies program, arises out of political interests of the time. The poverty programs, community action programs, the Civil Rights Act of 1964 ... these programs come out of this change at least, and in some cases radical change, in American consciousness about native and minority representation in all institutions.

CAC: Also known as cultural diversity.

GV: Right. The most accessible institutions at the time were universities. They were the most accessible to change because, of course, part of the constituency was absent but about to be admitted, etcetera, etcetera. It was a place where thought, original thought of these changes and ideas were being discussed. My point of this is not so much the obvious part of this that they are politically created but that they don't have really a place in the history of the university; so, they're very vulnerable. What's the most effective leadership? What do we expect from them? Do we want academic excellence? Do we want the kind of methodological and structural work that represents every field and discipline? This field didn't exist. This was a new field of study. Roger Buffalohead was quite right in articulating the importance of oral materials; but, it took almost a generation for that discussion to be realized in a sophisticated way, that it's not just the oral tradition that we're either resisting or embracing, but how can we approach oral materials? Surely not all oral materials are reliable, or even useful, or important. Some of them might be devious and dishonorable. So, that had to follow. Also, ordinary scholarship in the university was not necessarily the best kind of a source of leadership either. It was thought to be too abstract, too distant, and too objective, too methodological, unimaginative. It had nothing to do with natives. After all, natives have been dominated by this kind thinking for 500 years, etcetera, etcetera. You can see that the grand questions, if there are such grand questions, and the challenges to a kind of academic dominance over this subject itself, anthropology and the social sciences, and the way in which they interpret the meaning and representation of the other in American history had to be challenged, had to be overturned. We had to engage in a new discussion, a new sense of presence. All of that, day by day, was felt in the American Indian Studies programs. Day by day, you could feel these arguments because we didn't exist. We didn't exist. We were a promise-and we couldn't carry out the promise.

CAC: In the meantime, there wasn't a critical mass of students to justify ...? 
GV: Yes, there were. More than at any other time in American history, hundreds, thousands of native students were recruited to attend the University of Minnesota; but, the methods of recruiting, the promises about what it means to have a university education, the idea that they could only study natives, and that's what their business would be, and also that these were fairly generous stipends to attend, and many native students didn't have adequate preparation in public school, and the early support services were just not as effective as they are now ... for all those reasons, if I were recruited as a native student in a rural area ... "Here's a lot of money. Do you want to go to the university?" "Oh, hey, yes." It's complicated. Then, the difficulty of realizing that. Just anticipating the ordinary difficulties that any student would have coming to a large university would have been compounded by the kind of distance that a native student would feel. I try to put it in this context ...

CAC: I'm talking about a critical mass at the University of Minnesota. There probably was never a enough students committed and there at the same time to create a critical mass of support, horizontal with each other?

GV: Yes, that's right. They were all coming in about the same time in a few years. Whatever numbers there were, they were all at about the same level. There were very few people in graduate programs. You couldn't look up to somebody. The instructors at the university, the faculty at the university, I think with rare exception, were all in American Indian Studies. They weren't in other places. That's a change now. In those universities where native or American Indian Studies has survived, you have many more native scholars in the disciplines and then also some legitimacy built around the idea that the course of study itself, a kind of interdisciplinary study of native communities, cultures, and issues, is legitimate and important.

CAC: I'm guessing now that in 1996 in Minnesota the only department that still honors this tradition is History.

GV: Yes.

CAC: And we have one person [Jean O'Brien]. That's pretty lonely.

GV: American Studies did. They've tried to.

CAC: They couldn't hold.

GV: No, they couldn't hold.

CAC: May I make another suggestion and then have your response to it? American Indian Studies, I think, is the last of these special programs established chronologically.

GV: Yes. 
CAC: I think Women's Studies even preceded it?

GV: At Minnesota, I think it did, yes.

CAC: Someone doing this can check it out. It's not until the early 1970 s that it is accomplished?

GV: Right.

CAC: The first retrenchment is May 1971 and it's a small one, and 1973 is worse, and 1975. By the mid 1970s when the program is really getting underway, the money is running out.

GV: That's right, being cut back.

CAC: Cut back and a relative falling of state legislative appropriations. Tuition couldn't support it because there had to be scholarships for the minority programs. Federal funds are beginning to not disappear but be cut back. Did the Bureau of Indian Affairs ever put any money in these programs?

GV: Yes, they did; but, they put it in through the State Indian Education Committee. Minnesota was unique in this way that they had a State Indian Education Committee, which received applications for support. That's changed now. It's the tribes actually, the reservations, that make determinations on their enrollees and who gets financial support.

CAC: It's a terrible irony that by the time the will is there and the imagination to try something, then the financial resources are beginning to disappear.

GV: That's right.

CAC: As you know, you've been in all kinds of different university systems, it's the line departments, the provinces, that are the heart of the university.

GV: Yes.

CAC: They're going to cling onto their budgets and if there's going to be a reduction, you're not going to take it away from the main line departments. Obviously, some money is whittled away; but, the political power of these large departments . . wow! It's a terribly ironic story. Just at the time it gets going, and the will is there, and persons like Lukermann were really committed to it, the resources are gone or beginning to fade.

GV: Let's put that also in the context of the development of something of an intellectual history here. Here we come to the university-I'm going to take a first person on this - in a brand new department as if American Indian Studies was a discipline. Now, to say that in the context of, 
say, American intellectual history, we have to compete immediately with Anthropology, Ethnology, and other Social Sciences. They, that is those fields, have been the keepers of these tradition methods of looking at this subject of Native Americans from the beginning . . . a wide range of areas: demography, linguistics, archaeology, ethnography, cultural anthropology, law [unclear] of Hoebel, complex, primarily cultural anthropology. We come in and say, "We're a new discipline." What does that mean? We're a new department. We're a new course of study. What does that mean? By life experience, is that what that means? Okay, let's look at that ... our life experience. We're all mixed bloods. We all have complex personal experiences. We don't, let us say, come as a group from Chinle, Arizona, as native speaking Navahoes and come as a kind of family of traditional scholars, meaning that we've all politically worked out our sense of identity in a real community. I'm not faulting any one side or another. This is just comparative.

CAC: Yes.

GV: Even that approach has not worked all that well. The Navahoes set up their own Navaho community college. It's very difficult. They had to bring in scholars from the outside, of course. Where do you find the people who are experienced as teachers, who have a dedication to this? So, here we come ... late 1960 s, early 1970 s to a new department, a new discipline. How many people have experience teaching? Not many ... certainly not teaching Native American Studies. Thornton comes from Sociology. Buffalohead comes from History. In these early years, and it's still pretty much the case, anybody coming to these programs, this new assumed discipline, is coming from foundational fields, the traditional disciplines. They're trying to turn something originally in such a way that they both criticize the traditional disciplines of academic study and also say something new about what it is that we're doing. Now, all of this is not just interdisciplinary. It's not just that and it's not just eclectic.

Let me just comment on that. Consider the incredible responsibilities in an American Indian Studies Department. You've got everything: history, demography, health, science, astronomy, environment, myth, tradition, religion. Is there something that would be outside of the range of intellectual interest in American Indian Studies? No. Everything is in it. Do we know everything? Of course, of course ... we pretend we know a lot about certain things. Students demand a lot. The students demanded, for the most part, some special insight, something into the spiritual life, something into the tradition, which was different than the frustrations, and burdens, and responsibilities of a constitutional democracy. They wanted the ideals of a traditional society that had been wronged and here was a morally correct thing to do, to bring back these great traditions, to offer them in a classroom, as if that could be done. And also the irony that much of this material was presented, in the early years, as if it were sacred or spiritual. What is this? This is a secular university. Our business is to consider a number of possibilities, to challenge and discuss. This is not a place to teach single thought, religion, sacred things. It's to be comparative. Now, of course, we're more experienced and we look upon the responsibilities of native experience comparatively, different tribal groups, different areas, different times, synchronically, dichronically. At the time, the demands and responsibilities here 
for a brand new department like two, four, six years into creation ... [laughter] Much of our energy might have gone into, first, criticizing or so-called deconstructing the established methodologies of social sciences. In many of my courses today, that still is important, but not the significant part of it.

CAC: It's twenty years later.

GV: Yes. Now, it's trying to find a new theoretical approach to interpret in some way, to develop a kind of intellectual history of the diversity of native experience; and it's so broad and so complex. The demands here of being eclectic are understated. Eclecticism, generally speaking, in native departments is far more complex because it involves something of the sacred, the true belief, the essential, and something of criticizing, on the one hand, the generalizations of social science methodologies and, on the other hand, creating new generalizations that aren't any more effective or honorable ... new generalizations about native communities ... in other words, suppressing the diversity of very complex native cultures just to make a claim against some traditional academic field.

CAC: I'm going to suggest another complication there and that is that there was always among some non-Indian students and a smaller number of non-Indian faculty, a certain wannabee.

GV: Yes.

CAC: I'm thinking of Mr. [Arthur] Harkins in Education. Did you ever have any relationships with him?

GV: Oh, yes, many quarrels.

CAC: I felt so uneasy with Harkins.

GV: Yes. Arthur Harkins was a pain in the ass and he stole things from native communities, data.

CAC: How did he get in? Why did he do this?

GV: I don't know. Actually, I let him in on one occasion. He was very friendly and said he would put into key sort very complicated data we had acquired over the years in our center. We had a lot of information but we didn't have...

CAC: About students?

GV: No, about the people walking into the center. He took away these applicants and all of our paper work and never returned it. We had to sue the university to get it back. We finally got it back. He published it under his name, never cited its source or origins, took full credit for it. 
He did the same thing, I understand, in his dissertation. He took material from the White Earth Reservation, which had been gathered by native scholars there. They did a kind of survey of all the houses in the area and the families. Harkins came up and gathered up all that material; and it became the basis of his Ph.D. dissertation. If I remember right, he didn't thank the people who had done all of this work. He just sort of presented it as if he had done this work. He's a real despicable person.

CAC: It's interesting what became of him. When the Indian thing gave out ...

GV: He went to the future.

CAC: ... he went to the future. [laughter]

GV: Good place for him.

CAC: He became a futurist and people took him seriously there. He had a harder time stealing from the future.

GV: That's right, yes. He only has to change pronouns there.

CAC: Wow!

GV: He was invited by a southern Minnesota community-I can't remember which one-somewhere down around Winona ... he and Ed Magaw. Ed Magaw is a Lakota lawyer, a law school graduate, who was active in Indian education in Minnesota. Magaw was sort of working up a traditional act, the return to native traditions, the sun dance, [unclear], things like that among the Lakota, and had quite a following. If you remember, in the late 1960s and early 1970 s, the state passed this requirement that all school teachers had to complete every other year some seminar on ...

CAC: That's where Harkins got in.

GV: Oh, yes.

CAC: He was in the College of Education.

GV: Magaw and many of us were often invited by public schools to come give workshops and stuff like that on native cultures. Magaw had quite a following. The point of this story is that this southern Minnesota community-I think it was arranged by the Humanities Commissionbrought together Harkins talking about the future and Magaw talking about the sacred past. I couldn't resist this.

CAC: [laughter] 
GV: I was a journalist at the time; so, I went down on assignment for the Tribune and wrote this up. It was extraordinary. It was in April, just about tax due time. I was sort of guessing here. There were a lot of rural people there, farm people. So, Harkins did his let's escape from this vail of tears into a pure state of secular technology where everyone is equal . . great idealism of the future. What amazed me about his presentation and also many other futurists is that they never use the future tense. It's not conditional.

CAC: I see.

GV: It's something of an absolutism. It's faith in technology.

CAC: Now, we have Mr. [Newt] Gingrich, Speaker of the House, playing the same game.

GV: Yes, exactly. Then Magaw is talking about the Great Spirit, our ties to the earth, our return to the past. We have to give up the evils of technology and all these things that have distracted us from the true meaning of our lives and that's the essential earth.

CAC: You see how people could respond to that ... this whole hippie tradition out of the 1960s? That's a message that they wanted to hear.

GV: That's right. At the end, I was trying to guess, who is this audience going to go for? Are they going to go for the ideal separation into a great technology or are they going to go with this guy into a sweat lodge?

CAC: [laughter]

GV: They went with the guy to the sweat lodge. [laughter]

CAC: There's a kind of common sense in rural societies, communities.

GV: Yes.

CAC: You were present as the whole program fell apart?

GV: Yes.

CAC: You were saying earlier that you found a home in different places. Of course, you left, Thornton left, Beaulieu retired, and Buffalohead had already gone somewhere else to another kind of job. So, the whole thing was gone?

GV: Yes, in a year.

CAC: You were called in by the associate dean to kind of . . 
GV: In that last year, in the fall, Dean Lukermann put together a distinguished committee, a university-wide committee. I had experience in the ethnic studies department here. AfricanAmerican Studies at Minnesota and the Chicano-Hispanic program-I'm not sure what they called it at the time-were having difficulties in departments. Budget demands brought about this proposal. The thought was to consider something of an ethnic studies department where these different interests would come together and there would be larger numbers, stronger. At the time, my experiences here at Berkeley in ethnic studies were very positive, a very good approach.

CAC: That's when you're doing the winter here and fall and spring in Minnesota?

GV: Yes, right. Also, it could build in a kind of comparative strength and attract a wider interest of campus faculty members to participate and also graduate students in graduate courses, graduate programs. All of it felt good and seemed to me to be a pretty good approach at Minnesota. Lukermann put together this distinguished committee of university faculty to discuss this. We spent a couple of months in serious study of it, a lot of discussions and interviews with faculty from all of these programs.

CAC: Trying to find an alternative model?

GV: That's right. It all leaned toward some kind of collective or ethnic studies department. It didn't have to be called that. Its interests would have been stronger and its faculty more diverse. We needed more contact with each other anyway. Public consciousness about these issues was changing a bit, that there were a lot of things in common, etcetera, etcetera.

CAC: You could have had one secretary instead of four?

GV: Yes, right, there were good fiscal reasons to do this, too. Also building a strong graduate program would have given it stature. So, that was the recommendation of the committee. A good report was drawn. I insisted that the report be very brief-if I remember right, it was only about five pages - so that it could be read easily, understood. We aren't fooling around with 10,000 equivocal exceptions. It was absolutely turned down by everybody, by Black Studies, by Chicano-Hispanic, by Indian.

CAC: Oh, I see.

GV: Absolutely ...

CAC: The constituent groups wouldn't buy in?

GV: Not for a minute. So ... you, of course, know the outcome of that. All three of those programs pretty much disappeared.

CAC: Except the Afro-American. 
GV: Yes, but, it certainly could have been much stronger than it is.

CAC: So, the Berkeley model was not cheered on?

GV: No. The Berkeley model hasn't worked here very well right now with respect to Native American Studies; but, that's another discussion. There aren't many parallels there to what happened at Minnesota. That was pretty much the dissolution of American Indian Studies. I was very sad. I have to tell you that the support the university gave this department was considerable and dramatic: a whole floor in the Social Sciences Tower, secretarial, language, equipment, on and on. It's embarrassing, on the one hand, that such generous support failed and that there was so little honor of the material part of it.

CAC: You had a floor but you had a few professors who couldn't find an office anywhere else who were put on that floor.

GV: Yes, that's right.

CAC: I was one of them. When I ceased being chair, I lost my chairman's office and they stuck me on this floor. I think I was the only non-Indian.

GV: That was near the end when we were ...

CAC: Every other Friday or something like that, they had a lunch . . . served hot food. I forget who it was . . . he'd always come by and knock on my door and say, "Come down and eat with us"-which sometimes I did. [laughter]

GV: There's another feature of this experience in American Indian Studies as a department that I don't think many other faculty members appreciate. I'm sure they've had experiences like this in other contexts in the formation of a university; but, it's way beyond memory, and that is, what happened on a reservation. The politics of families and communities on reservations had an immediate and direct bearing on the business in the department. Gossip. Family business. Who's who? Who said what? Who's doing what? How they betrayed this or that . . There was just an unbearable intensity and burden of gossip, unbearable.

CAC: Which would be true of tribal governance, societies and in many places?

GV: In any case, yes. If you're teaching in history, of course, you have to deal with the community now and then, whatever the community is but the politics of it? Not likely. Not likely. That might have been one of the most destructive forces in the department. Here at Berkeley, for instance, the so-called community-which was no community at all; it was a group of highly radical self-interested people-would show up at our faculty meetings and vote. Luckily, we sort of ignored their vote, and kind of danced around it, and did what we wanted to do anyway. Sometimes, we couldn't. We'd bring up a name of somebody and the community 
would organize, and gang up in the meeting, and finish that off without even any discussion. It really complicated it. We managed to get through that. Minnesota was a bit like that. Powerful community interests literally sabotaged sometimes if you took an unpopular position on something. Records would be lost, files would be lost, things would happen. There was a woman named Rose Shingabee who taught Language. She taught Anishinabe. She was a formidable person, very strong-willed, very outspoken, active in the community. She went to mission schools at White Earth. She had a wavering tolerance and hatred of me for no known reason. We had very little contact and it was always cordial in a ...

[End of Tape 2, Side 1]

[Tape 2, Side 2]

GV: Rose Shingabee was known to me. I knew her in the community; but, I had never had any contact with her, never adverse, nothing I knew of. Of course, I'm sure things that I said or wrote must have...

CAC: Or family [unclear]?

GV: That's what it was. It was one of my relatives, Joe Vizenor, who was tribal business manager. That was the name for being something of a tribal chair at the time, back in the 1950s. He did something to her family that she never forgot. I don't know what it was. Because I was a relative, I inherited her anger about this. She would, at meetings, just sort of turn into a critical mass about me. It was awful. I never quite knew when it was going to erupt and how it would affect the whatever it was we were doing at the moment. Often, I would have to leave the room.

CAC: This may not be an appropriate place to suggest it; but, many small groups are driven by these kinds of jealousies, and envyings, and feuds. You can't imagine a more rational department than the Department of History and some of the things you've been describing, I could match story for story.

GV: They would have taken place there, yes.

CAC: Things would flair up and I'd have no idea where they were coming from, particularly when I was chair.

GV: I used to say to my colleagues that any other department has as much intrigue, compromise, duplicity. The difference is we're new. We don't count. We exist as a political favor.

CAC: You have those lines out in the community which the Department of History would not, as you commented earlier.

GV: That's right. 
CAC: We had money and that helped.

GV: That's right, yes. The other argument I've taken is that if American Indian Studies is ungovernable, it disappears. If History or English is ungovernable, they bring in somebody from the outside because they must have History.

CAC: Of course.

GV: No matter the politics, they'll have History. That's a big difference. Nobody invited or needed, that is to say ...

CAC: When I came to Minnesota in 1951, we were a department of seventeen or eighteen and, now, we're a department of forty-five or forty-eight counting people who are part-time. What happened in the 1960s was the break down of patriarchal governments because the size got beyond it and the old folks were retiring and dying so that there had to be a change there. One thing that militated, in my judgment, against this kind of factionalism, which is always destructive, was that under Stuart Hoyt, who was my predecessor in the chair, and then under my chair, we opened the department up. I was the first person to publish the whole budget so that everybody could see it.

GV: Very good.

CAC: Instructors, full professors ... they all saw it. Once we saw who was making what, then there wasn't so much gossip running up and down the corridors.

GV: Yes.

CAC: There were other issues; the budget was crucial. We also introduced a system by which all ranks discussed the promotion of all ranks. It wasn't by rank superior. Once that was done, it was open, and people knew better what the criteria were, and because everybody was hearing it, you didn't have to hear it . . "Oh, you know what so and so said about you!" Everybody heard everything. It wasn't always kindly and it wasn't always accurate; but, at least it didn't have that ...

GV: Conspiratorial.

CAC: ... subversive quality that tears things apart.

GV: Let me do an interesting parallel there. When I was running that community center, that store front in the Indian community, what was about to destroy our good efforts was subversive, negative gossip. It was around budget. It was about how we were all stealing. This was just horrible because we were so dedicated to the honor of this and very, very careful because we knew we were under scrutiny. It was so devastating because we were doing such good work, 
wanted to do it, dedicated to doing it. It needed to be done and we were being defeated by the gossip of it, by the envy and jealousy of it. I published weekly the entire budget, and ran off spirit duplicated copies of it, and posted it on bulletin boards and store windows all over the community. It stopped for a little while, this subversive gossip about how we were stealing the money; but, then it started up again, notwithstanding this weekly published balance sheet. We didn't have much money to begin with. It was $\$ 20,000$ for the year. It was amazing. Then, I figured it out. We set aside a certain amount of money in a cash account because we had people coming in in emergency.

CAC: Of course, the bishop's discretionary fund.

GV: We just had to have that. We'd give five, ten, twenty, thirty dollars to individuals and families for emergency food and things like that. That's where the gossip was focusing now, that we were ripping this off; so, I published weekly by name and the amount of money that people received and added that to our balance sheet. That ended the gossip. We went for a couple of years without anymore negative gossip.

CAC: You know better than I now that there's big money through the casinos, boy! I'll tell you that's kind of ...

GV: It's tearing communities apart.

CAC: White Earth ... You had suggested before we turned this machine on that you were a representative on HECB, the Higher Education Coordinating Board in the late 1970s, 1976 to 1980. Do you want to say anything about that experience, which took you out of the University of Minnesota? Then, that's kind of a closing note I would guess.

GV: It brought me in contact with senior administrators in all the universities and colleges in the state, which was quite interesting, and state politicians. I think probably the most memorable experience was the proposed termination of Southwest State University in Marshall. The governor decided that the demographics of that area supported the idea that it would continue to decline in enrollment and population and, therefore, let's close it up and save some money. My view of how this came about is that Governor Wendell Anderson named David Lebedoff to the Higher Education Coordinating Board just before our meeting at Southwest State where it would be announced that they were going to have hearings about closing it; so, he was sort of carrying the message from the governor that this university should be closed. At that hearing in Marshall, the state sent down all its experts on communities, its demographers, its statisticians; and they put together a very convincing formal presentation on the decline of this part of the state, and how it would have a direct impact on the university, and, therefore, it should be closed to conserve resources and state budget, etcetera. Naturally, the community was horrified at such a thought, to have somebody from St. Paul come down and tell them that they're dying and disintegrating. 
CAC: It's the heart of the payroll for the whole county.

GV: Yes, right. They had great pride and they saw their community growing. They saw this is as a growing university; they didn't see this as death and dying. [laughter] The metaphors were in absolute contradiction here; but, the community was very fair-minded, and generous, and friendly. There was no angry denunciations. I listened to these experts and always had some suspicion of experts who dealt with numbers anyway. I listened very carefully and anticipated what I thought would be their weakest points. I said, "What you're telling me is that you're using past data to divine the future." That created some interesting laughter in the audience and also created a little tension among the experts because they had to find a way now to say that what they were doing was not divining...

CAC: But was projecting. [laughter]

GV: . . . was projecting with solid kind of stuff. Once having them trapped into their own argument in this way where they couldn't get out by saying, "There are certain myths that explain things," I then said, "What impact do you think the Vietnam War had on all of the predictions that people made about communities?" "What do you mean?" I said, "What I mean is, could you have anticipated with your data such a thing as the Vietnam War?" "Of course not." I said, "The war drew all kinds of young people out of these communities and now you're telling me they're not going to return. How do you know that? What if something else extreme happens somewhere else and they find coming back to this grand part of the country a real advantage? Cities are unlivable. Pollution is so great. The myths of the country shift. So, what happens to your data? In other words, you don't really know what you're talking about." I just kept on this and I had a great time because they were so absolutely secure in the truth of their data that they were, in fact, very vulnerable to just the subtlest kinds of questions. Finally, I recall, I was persuasive-of course, I've improved on this story because it's a abbreviated; it went on for a couple of days there-by pointing out that there was no way to anticipate the extremes and that, in fact, histories of this kind are determined by extremes not by gradual changes that you're suggesting and, in fact, this community could just as well put together a way to bring people here as to fulfill your predictions that people will leave. What I realized was that David Lebedoff was on this board now not just as a stepping stone to the regents of the University of Minnesota, which is what he aspired to, but to help do in Southwest State on behalf of the governor. I was about to block that with all these questions. So, David Lebedoff sort of took over in a very generous manner my points of view and would sort of retell them.

CAC: [laughter]

GV: He'd say, "I think what Mr. Vizenor means to say is . . ."

CAC: He was a good lawyer. 
GV: Yes. I invited him out to the hallway and told him in very sharp terms, "Enough of this. You say another word about anything I'm saying and I'll betray everything . . . explaining your presence here." That sort of ended our possible friendship; but, it also quieted him down a bit. As you know, it didn't close and I always felt like I . . there are a few small moments in one's life where you feel you've been just a bit . . .

CAC: When you behave well.

GV: Yes.

CAC: You haven't thought of those things to say when you got home?

GV: That's right, yes. I did well there. I did well by that community and they remember me for that.

CAC: Do you know the next chapter?

GV: No.

CAC: The next chapter is they hire as chancellor or president, whatever they call him, a Ph.D. in Ag[riculture] Econ[omics] I think, who had been in the Secretary of Agriculture's office in St. Paul, a part of state government, a very able young man. He went down there and said, "We're going to die unless we get a focus here and do something that no one else is doing."

GV: Very good.

CAC: And he said, "What is it? We're a rural county. We're a rural region. We're going to put everything around farming, rural culture, the sociology, the literature, the history."

GV: Very good.

CAC: He got everybody down there to retool.

GV: That's right! In literature, I recall that it focused on agrarian literature.

CAC: Yes. In History, they set up an archive center on rural history, and they went around interviewed all these people, and they got a program in History-undergraduate; they have no graduate program there at all-of doing interviews, and then writing little histories. They somehow got the money and they published these rural histories that undergraduate students were writing as their senior paper.

GV: Oh, that's terrific. 
CAC: It was something!

GV: That's great.

CAC: That's what held it. It's one of the better ...

GV: State universities.

CAC: I'm sure you know also that the joke is that of all the community colleges, state university campuses, the University of Minnesota and on several campuses, only one has ever been closed and that's Waseca.

GV: Yes.

CAC: That's the only one. Let me remind the listener here, if they've been listening to other tapes, that what I've caught from so many interviews, that it was in the early to mid 1970s precisely when the money was beginning not give out but to decline and the pressures were on that the state legislature made the decision to have an institution of higher learning, that is, past secondary, no farther away for any student than thirty-five or forty miles; so, you were going to have a junior college, a community college, a vo[cational] tech[nical], a state university, a campus of the University of Minnesota so that every student can live at home and go to these. It took the money away; it spread it all around the state. Representatives and senators from outstate then come not to look at the University of Minnesota as the flagship, as we like to say, but Mankato State, [unclear], Crookston ... all these places.

GV: Yes, as a transfer, right.

CAC: Their loyalty is there to see that they're well taken care of. It dispersed the funds at the university. This is one of the troubles the university got into. God! Mr. Vizenor, it's a long story. It did drift into things on the circumference; but, that's all right.

GV: It was a good discussion.

CAC: I thank you.

GV: I'll just put in context, in closing, my experience as a teacher, which whoever is going to listen to this might ... My first teaching experience was at Lake Forest College in Mlinois. Then, I came back to the reservation, and worked in teacher training programs, and then directed the first Indian Studies program at Bemidji State University in 1970 or 1971. Then, I taught at [University of] California, and then returned to Minnesota, and then later returned again to California, to Berkeley and Santa Cruz, and I continue to teach now ... .

CAC: Oklahoma for awhile? 
GV: Yes, I was at Oklahoma for a year on an endowed chair appointment. Altogether, I've probably been at Berkeley about ten to fifteen years, full- and part-time.

CAC: You're in your early sixties, now?

GV: Yes, sixty-two in the fall.

CAC: That's an exciting career.

GV: It has been.

CAC: In your case, at least, I'm sure that the writing has been as important a reward to you as the teaching and all the other things that go with it.

GV: It's been the heart of my interests to change not only the record but to weave a different memory of native experience. I've been successful there ...

CAC: Extraordinarily successful.

GV: . . way beyond what I ever could have imagined.

CAC: When did you realize that that could be a possibility for you . . chronologically? When did you realize that with short stories, and novels, and essays, and criticism, and theory, and poetry you could break out and give the country another voice?

GV: Two brief answers . . one, it's the moment at which I can think of myself as a writer. Not everyone can call up that memory; but, I do have strong memory of that moment. Then, also the moment at which you think your writing has or could have some significance. One was in tenth grade in public school when I wrote a piece of realism. It was pretty much just a descriptive linear account, a kind of story, of my going to-underage-the Minnesota National Guard summer training camp at Camp Ripley. Of course, at sixteen years old and underage, this was an extraordinary and exciting experience. Also the breathlessness of the lie . . . will I be discovered?

CAC: [laughter] You got away with it?

GV: I got away with it. No one else at sixteen had such an experience. I was in charge of great experiences here. I wrote this up on an assignment for kind of an imaginative story of life experience; and the teacher returned it, and refused to accept it, and said she wanted life experience not lies. I didn't know at the time that what I was doing was writing realism. One doesn't just write realism; you have to have a reader who believes it. This later, I came to understand is one of the most critical problems-we call it representation-about natives in literature and history. Their presence in popular culture in literature and history is so well- 
established and wrong. You can't just write realism, or essential truths, or this or that. You have to find a voice. The voice I've tried to develop is one that arises from something in tribal storytelling, a different kind of style. That's what I've been trying to do . . . more successfully with some efforts than others. The effect of writing, I think, came to me in the military when I started writing and realized that it does have power. I learned this not only by writing but by reading.

CAC: You were writing for a GI newspaper?

GV: Yes, occasionally but I was writing poetry, short stories, and plays for the military.

CAC: Getting published at that early time?

GV: No, no, they weren't published.

CAC: But, you knew their potential?

GV: I felt in the story as I wrote them a kind of power, that this was a place that I could be, a kind of power I could be, and that was important to me, and that I might be able to change things and leave something that revealed this, what I considered to be, a unique experience, a different interpretation, a different way of telling things. That has been the case.

CAC: With the printed word, you've touched tens of thousands of people who have never seen you.

GV: I do it in a way that's surprising to them. I challenged what I consider to be simulations and false representations in a way that I feel as if I've had a very powerful and dramatic effect upon not only my students but on people who read me.

CAC: But, it's complicated your relationship with different tribal persons?

GV: Yes. That, I didn't know in my lifetime, in fact, if I could or would be honored for this kind of challenge to natives themselves; but, it looks as if I might be. The past five years, there's very little of this anti-intellectualism anymore. Natives, at all levels, are taking up complex ideas, theoretical ideas. They're taking up the challenge of what they thought to be a kind of essential truth and trying to develop new and original thinking about their own communities while at the same time challenging existing histories. That's not enough. You have to come up with a better interpretation, a better methodology, or a different one anyway.

CAC: There are powerful persons who don't like to be revealed.

GV: Oh, boy! are there ever. Luckily, I've had tenure so I could get away with it. I've taken on some pretty significant people in this area. 
CAC: Strength to your elbow!

GV: [laughter] Long at the tooth and a strong elbow? Thank you, Clarke.

CAC: Right. Mr. Vizenor, I thank you.

[End of Tape 2, Side 2]

[End of the Interview]

Transcribed by:

Hermes Transcribing and Research Service

12617 Fairgreen Avenue, Apple Valley, MN 55124

(612) 953-0730

Gerald Vizenor Interview 